NASA TECHNICAL MEMORANDUM
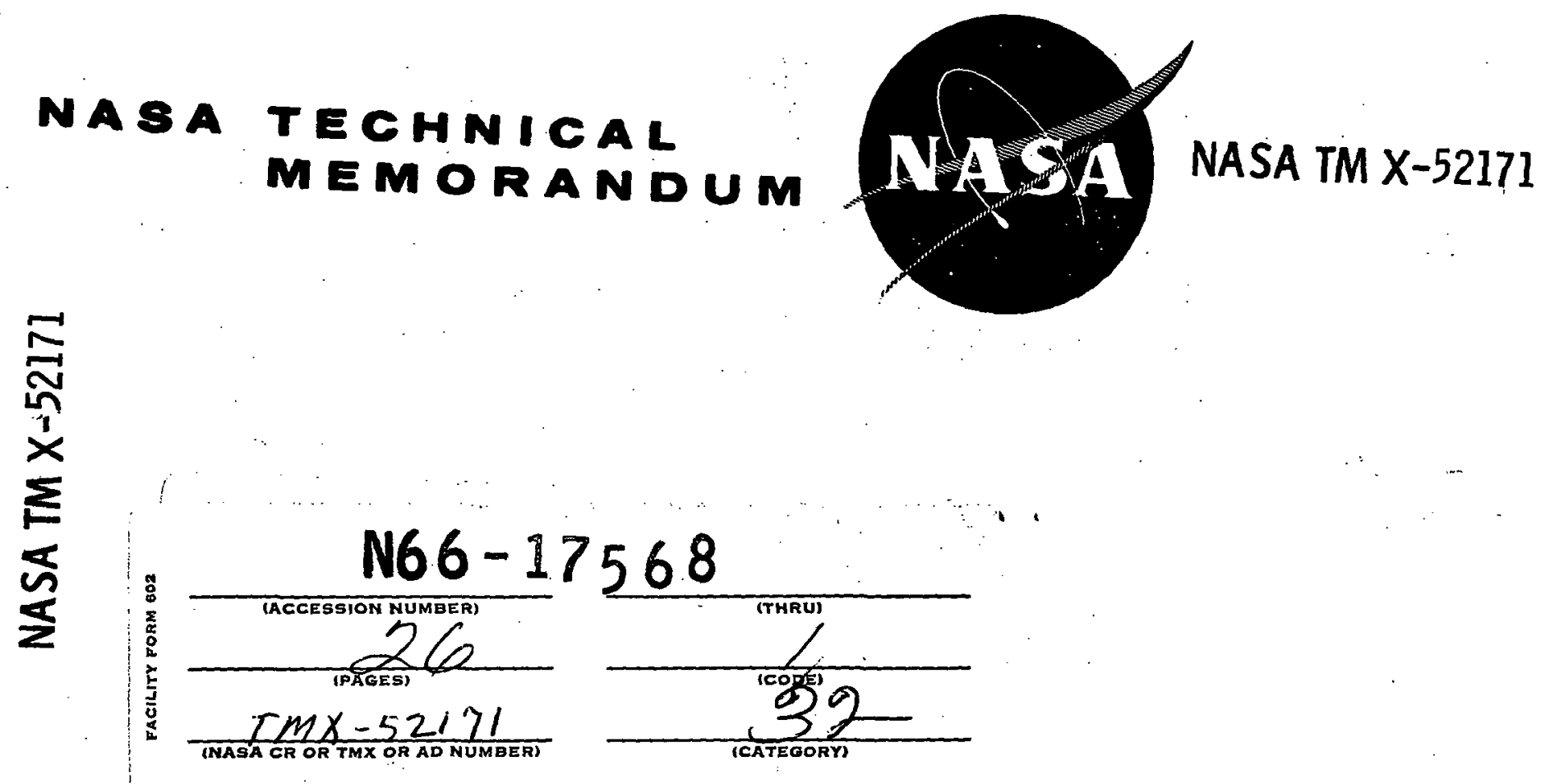

\section{FILAMENT-OVERWRAPPED METALLIC CYLINDRICAL PRESSURE VESSELS}

by Robert H. Johns and Albert Kaufman Lewis Research Center Cleveland, Ohio

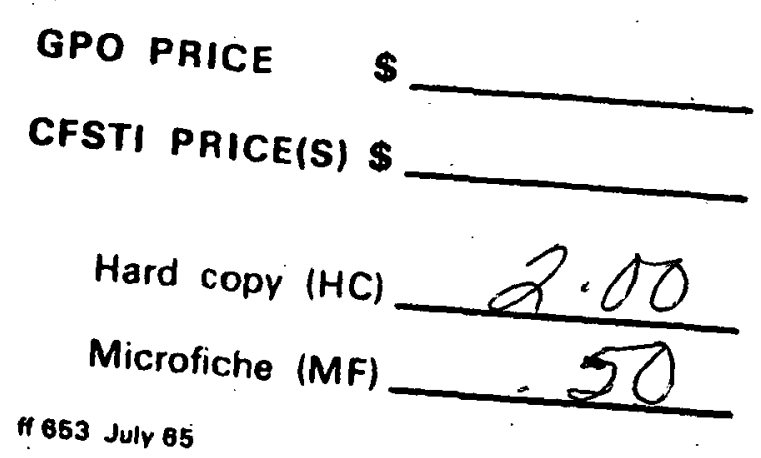

TECHNICAL PAPER proposed for presentation at Seventh

Structure and Materials Conference sponsored by the American Institute of Aeronautics and Astronautics and the American Society of Mechanical Engineers Cocoa Beach, Florida, April 18-20, 1966 
FILAMENT-OVERWRAPPED METALLIC CYCLINDRICAL PRESSURE VESSELS

by Robert H. Johns and Albert Kaufman

Lewis Research Center

Cleveland, Ohio

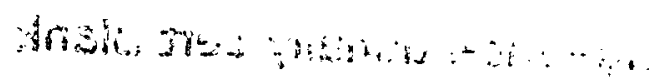

TECHNICAL PAPER proposed for presentation at

Seventh Structure and Materials Conference

sponsored by the American Institute of Aeronautics and Astronautics

and the American Society of Mechanical Engineers

Cocoa Beach, Florida, April 18-20, 1966 
FILAMENT-OVERWRAPPED METALLIC CYLINDRICAL PRESSURE VESSELS

by Robert H. Johns and Albert Kaufman

Lewis Research Center

National Aeronautics and Space Administration

Cleveland, Ohio

\section{INTRODUCTION}

Glass-fiber-composite materials are attractive for certain structural applications because of their relatively high strength-to-density ratios. However, they would not normally be impervious if used for the containment of liquid cryogens in propellant tanks or pressure bottles. Current research indicates that a suitable liner for use in fiberglass composite, liquid-hydrogen propellant tanks may eventualiy be developed. At this time, however, no liner is available that can reliably withstand a sufficient number of cycles at the 2- to 3-percent strain assoc1ated with the use of highly efficient glass-fiber-composite structures at these temperatures.

Another approach exists which permits taking advantage of the attractive properties of glass-fiber materials for cryogenic pressure vessels. This approach consists of wrapping a metallic vessel with glass fibers in such a way that the metal supports a large part of the pressure load as well as being used for an impervious liner. By prestressing the glass fibers to put the metal into precompression, the problems associated with the difference between the yield strains of the two materials can be largely overcome.

This paper is concerned with the design of filament-overwrapped metallic cylindrical pressure vessels. The purpose of the paper is to determine some of the advantages, as well as disadvantages, of overwrapped pressure vessels and to evolve some design guides as to material and geometric considerations.

One of the first suggestions for the use of filamentary windings on metallic pressure containers in aerospace applications is presented in ref. 1. The concept described used glass-filament windings at the intersections of spherical segments to carry the unbalanced radial component of the membrane load. The major advantage of such a concept is that pressure vessels of many shapes can be made with efficiencies $\mathrm{pV} / \mathrm{W}$ as high as, or perhaps higher than, those of homogeneous metallic spheres. Further theoretical work on the same concept but using bulkheads instead of reinforcing rings is described in ref. 2 .

Some experimental results for pressure vessel efficiencies of fiberglassoverwrapped metallic cylindrical pressure vessels are presented in ref. 3 . Some prac- h tical aspects of winding, testing, and using this type of composite vessel are discussed. Ref. 4 provides an elastic-plastic stressstrain analysis using the incremental theory of plasticity for hoop-wound metallic cyIndrical pressure vessels. A numerical method for computing stresses and deformations up to the burst pressure is outlined. Experimental tests were made to verify the theory; agreement between theory and experiment was excellent.

Ref. 5 presents a brief discussion concerning some of the potential weight savings that can be obtained with filament-

overwrapped metall1c pressure vessels. The use of anisotropic metallics, along with various filamentary materials, is considered.

The filament-overwrapped pressure vessels used as examples in this paper are circular cylinders of aluminum, wound with an amount of glass sufficient to carry about one-half of the hoop load at burst pressure. The 2014-T6 extruded aluminum tubing over which the S-HTS glass was wrapped was thus designed to be in a one-to-one blaxial stress field at burst pressure.

Theoretical analyses are presented for pressure vessel efficiency as a function of material properties. Included as part of the study is the consideration that the metal can fail because of buckling, which is induced by residual tensile stresses in the filaments, as well as in tension from the pressure load. Experimental buckling data are reported for tests of thin-walled circular cylinders loaded by radial pressure resulting from pretensioned filamentary windings. Possible reduced pressurevessel efficiencies, based on the fact that the proof pressure may be limited by the buckling strength, are also calculated. Safety factors based on material stresses are compared with safety factors based on pressure ratios. Burst tests are made on fiberglass-overwrapped metallic tanks at room, liquid-nitrogen, and liquid-hydrogen temperatures. The results of these tests are then compared with theoretical predictions of the burst pressures.

\section{SYMMOIS}

a radius, in.

E modulus of elasticity, $1 \mathrm{~b} / \mathrm{in} .^{2}$ thickness, in. 


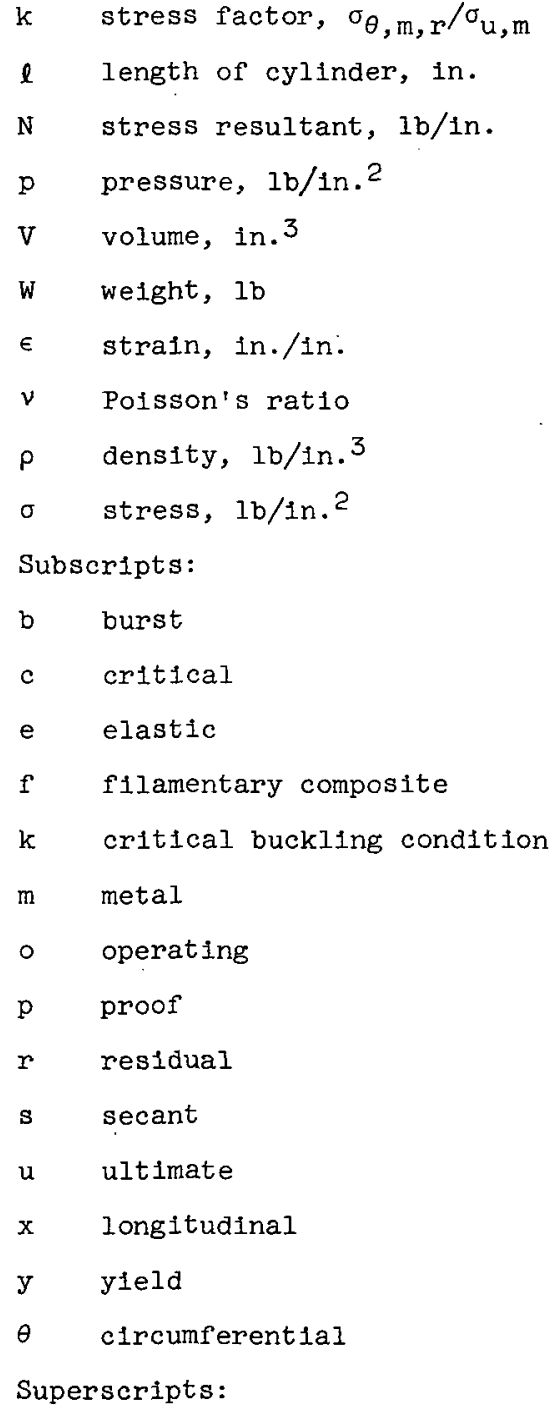

(-) true

\section{STRESS ANALYSIS}

In a conventional metallic cylindrical pressure vessel, the stress in the axial direction is half that in the circumferential direction. The metal is thus able to cerry about twice as much load axially as it is called on to support. When the metal is isotropic, the pressure vessel would be more efficient if the stresses in the two principal directions were more nearly equal. Such a situation exists in a spherical shell where the "pressure vessel efficiency" or "figure of merit" is

$$
\frac{p V}{W}=\frac{2}{3} \frac{\sigma}{p}
$$

In a conventional long cylindrical shell, in which the effect of the ends can be neglected, the efficiency is

$$
\frac{\mathrm{pV}}{\mathrm{W}}=\frac{1}{2} \frac{\sigma}{\rho}
$$

The possibility of wrapping a metallic cylindrical pressure vessel circumferentially with filamentary windings to make it more efflcient than a spherical shell will be investigated. It will be assumed that sufficient windings are applied to carry half of the hoop load. The metal carries all the axial load and thus is in a 1-to-l stress field.

\section{Elastic Case}

Assume the vessel is overwrapped with essentially no prestress, that a l-to-l stress field exists in the metal at all times, and that the material stresses never exceed the elastic limit. Then,

$$
\mathrm{N}_{\mathrm{x}, \mathrm{m}}=\mathrm{N}_{\theta, \mathrm{m}}=\mathrm{N}_{\mathrm{f}}=\frac{\mathrm{pa}}{2}
$$

Compatibility of displacements requires that the hoop strain in the metal be the same as that in the filamentary windings. This results in $\epsilon_{\theta, m}=\epsilon_{\mathrm{f}}$ or

$$
\frac{\left(1-v_{m}\right) p a}{2 E_{m} h_{m}}=\frac{p a}{2 E_{f} h_{f}}
$$

Thus,

$$
\frac{h_{f}}{h_{m}}=\frac{1}{\left(1-v_{m}\right)} \frac{E_{m}}{E_{f}}
$$

The pressure which causes yielding in the metal is

$$
p_{y}=\frac{2 \sigma_{y, m^{h}} \cdot m}{a}
$$

For a long cylinder (neglecting the ends),

$$
\frac{\mathrm{p}_{\mathrm{y}} \mathrm{V}}{\mathrm{W}}=\frac{2 \sigma_{\mathrm{y}, \mathrm{m}^{\mathrm{h}} \mathrm{m}}}{\mathrm{a}} \frac{\pi \mathrm{a}^{2} \ell}{2 \pi \mathrm{a} \ell\left(\mathrm{h}_{\mathrm{m}} \rho_{\mathrm{m}}+\mathrm{h}_{\mathrm{f}} \rho_{\mathrm{f}}\right)}
$$

or

$$
\frac{p_{y} V}{w}=\frac{\sigma_{y}, m_{m}}{\rho_{m} h_{m}+\rho_{f} h_{f}}
$$

Substituting equation (5) into equation (6) gives

$$
\frac{p_{y} V}{W}=\frac{\sigma_{y, m}}{\rho_{m}+\frac{E_{m}}{\left(I-v_{m}\right) E_{f}} \rho_{f}}
$$




$$
\frac{E_{m}}{\left(1-v_{m}\right) E_{f}} \rho_{f} \leq \frac{1}{2} \rho_{m}
$$

then

$$
\frac{p_{\mathrm{y}} \mathrm{V}}{\mathrm{w}} \geq \frac{2}{3}\left(\frac{\sigma \mathrm{y}}{\rho}\right)_{\mathrm{m}}
$$

that is, the efficiency would be equal to or greater than that of a spherical pressure vessel. Equation (8a) can be rewritten as

$$
\left(\frac{E}{\rho}\right)_{f} \geq \frac{2}{\left(1-\nu_{m}\right)}\left(\frac{E}{\rho}\right)_{m}
$$

Strain compatibility expressed in equation (4) results in

$$
\left(\frac{\sigma}{E}\right)_{f}=\left(\frac{\sigma}{E}\right)_{m}\left(1-\nu_{m}\right)
$$

Multiplying equation ( $8 \mathrm{~b}$ ) by equation (9) and recalling that all stresses must remain elastic give

$$
\left(\frac{\sigma}{\rho}\right)_{\mathrm{f}} \geq 2\left(\frac{\sigma}{\rho}\right)_{\mathrm{m}}
$$

For the two materials to act together elasticaliy and to be at least as efflcient as a spherical pressure vessel, equations ( $8 b)$ and (10) must be satisfied. Filamentary composites that satisfy the strength-todensity restriction of equation (10) can readily be found. The modulus-to-density restriction of equation ( $8 \mathrm{~b})$, however, is not so easy to comply with. Only relatively new and untried materials, such as boron or carbon filaments; meet this requirement. For instance, $E / P$ for most common structural metals as well as S-HTS glass composite is $10^{8}$ in., whereas for boron or carbon filamentary composites, it is about $7 \times 10^{8}$ or $8 \times 10^{8}$ in. Thus, whereas $E / \rho$ for the filamentary composite should be about $2 \frac{1}{2}$ to 4 times that of the metal, for most avallable materials the ratios are about the same. Consequentiy, overwrapped cylindrical pressure vessels which behave elastically at all times in a highly efficient manner are not practical at this time.

\section{Inelastic Case}

In this section, overwrapped vessels which flow plastically on the first cycle but operate elastically thereafter will be considered. For this case, the materials will typically behave as shown in fig. 1 . During the initial part of the pressurization cycle, both the metal and filamentary overwrap will act elastically along the linear portions of the stress-strain curves. For the case where the overwrap is designed to carry half of the hoop load at burst pressure, most structural metals will generally yield when the pressure is about half of the burst pressure; this depends on the strain-hardening characteristics of the metal. The metal will then flow plastically, and the materials will strain to the line designated "proof strain". On release of the pressure, the materials will unload elastically parallel to their original loading lines. The residual stresses and strains will then lie along the line designated "strain at zero pressure after first cycle" with residual compressive stresses in the metal and tensile stresses in the filaments, as shown in fig. 1 .

It is assumed that the proof pressure will be higher than any subsequently applied operating pressures. If so, the materials will then operate elastically in the range designated "operating strain range" in the figure. If the proof pressure is later exceeded, the materials will strain along continuations of the original stress-strain curves with further plastic flow taking place in the metal. Assuming the vessel does not fail, a different state of stress will exist in the materials when the pressure is released than exists prior to the additional plastic straining.

The derivation of the following equations, which govern the behavior just described, will not be presented here because of space limitations. They will be derived in a subsequent publication. The pressure vessel efficlency obtainable at burst conditions, based on uniaxial strength data, is

$$
\left(\frac{p_{b} v}{W}\right)_{u}=\frac{\left(\frac{\sigma_{u}}{\rho}\right)_{m} \cdot\left(\frac{\sigma_{u}}{\rho}\right)_{f}}{\left(\frac{\sigma_{u}}{\rho}\right)_{m}+\left(\frac{\sigma_{u}}{\rho}\right)_{f}}
$$

Equation (11) assumes that both the filamentary composite and the metal fail simultaneously. If the vessel is fabricated with just enough overwrap to carry half of the hoop load at burst pressure and is proofed to a pressure just below burst, the residual stress in the metal, on unloading, will be

$$
\sigma_{\theta, m, r}=-k_{u} \sigma_{u, m}
$$

where

$$
k_{u}=\frac{\frac{E_{m}}{E_{f}}-(1-v) \frac{\sigma_{u, m}}{\sigma_{u, f}}}{\frac{E_{m}}{E_{f}}+\frac{\sigma_{u, m}}{\sigma_{u, f}}}
$$

or

$$
\mathrm{k}_{\mathrm{u}}=\frac{\epsilon_{e, f, u}-(1-v) \epsilon_{e, m, u}}{\epsilon_{e, f, u}+\epsilon_{e, m, u}}
$$

in which

$$
\epsilon_{e, f, u}=\frac{\sigma_{u, f}}{E_{f}}
$$


and

$$
\epsilon_{e, m, u}=\frac{\sigma_{u, m}}{E_{m}}
$$

Equation (13) is based on the assumption that the glass is linearly elastic to failure. From equilibrium considerations, the residual stress in the filamentary composite will be

$$
\sigma_{f, u}=-\frac{h_{m}}{h_{f}} \sigma_{\theta, m, r}
$$

Ordinarily, the vessel will probably not be proof tested to near-burst conditions. However, if such a situation needs to be considered and buckling of the metal shell on unloading becomes potentially critical, the compressive stresses can be reduced from those given by equation (12); that is, the vessel can be modified slightly with additional filamentary windings to have the same proof and burst pressures but to have reduced compressive stress in the metal on unloading. If buckling may be a problem, the allowable compressive stress the metal can withstand will presumably be known, as discussed in the section COMPRESSIVE BUCKLING. The compressive stress ratio will then be

$$
k=-\frac{\left(\sigma_{\theta, m, r}\right) \text { allowable }}{\sigma_{u, m}}
$$

It can be shown that the thickness of filamentary composite necessary to restrict the compressive stress, if the proof pressure is near the burst pressure, is

$$
h_{k, f}=\frac{\sigma_{u, m}}{\sigma_{k, f, b}} h_{m}=\frac{1-k}{1-v+k} \frac{E_{m}}{E_{f}} h_{m}
$$

assuming the hoop stress in the metal does not vary significantly with strain near the proof pressure. The corresponding stress in the filamentary composite at burst pressure is

$$
\sigma_{k, f}=\frac{1-v+k}{1-k} \frac{E_{f}}{E_{m}} \sigma_{u, m} \quad k \leq k u
$$

The additional filamentary windings added to reduce the compressive stress in the metal on unloading also reduce the pressure vessel efficiency below that given by equation (11). The resulting efficiency is

$$
\left(\frac{p_{b} V}{w}\right)_{k}=\frac{\left(\frac{\sigma_{u}}{\rho}\right)_{m} \cdot\left(\frac{\sigma_{k}}{\rho}\right)_{f}}{\left(\frac{\sigma_{u}}{\rho}\right)_{m}+\left(\frac{\sigma_{k}}{\rho}\right)_{f}} \quad k \leq k_{u}
$$

This can also be expressed as

$$
\left(\frac{p_{b} v}{w}\right)_{k}=\frac{\lambda \sigma}{u_{,} m} \quad k \leq k_{u}
$$

where

$$
\lambda \equiv \frac{1-\nu+k}{1-k} \frac{E_{f}}{E_{m}}
$$

A plot of pressure vessel efficiency ratio against a dimensionless allowable metal compressive stress in shown in fig. 2 for an aluminum cylinder overwrapped with S-HTS glass composite and proof stressed to nearburst at $-320^{\circ} \mathrm{F}$. It is indicated here that this overwrapped cylinder can be as much as 65 percent more efficient than a long aluminum cylinder or 23 percent more effecient than an aluminum sphere. The maximum compressive stress in the metal in the unloaded condition for the most efficient vessel would be about 70 percent of tensile ultimate, if the vessel were pressurized almost to burst on the proof cycle.

Situations may occur where a pressure excursion beyond the proof pressure may need to be considered but where buckling of the shell on unloading from that pressure may be tolerable. Fror instance, from the aspect of safety, buckling may be permissible when the pressure is very low or nonexistent, as long as the unexpected high pressure is contained. For this case, additional filament windings, which would be necessary to reduce residual compressive stresses, would not be added, and thus the pressure vessel efficiency would not be reduced. It is very probable that for highpressure vessels, the proof pressure will be considerably lower than the burst pressure. Buckling may need to be considered only for pressures below the proof pressure. For these conditions, fig. 2 would give unduly conservative results; in fact the pressure vessel efficiency might not be reduced at all.

\section{TENSILE INSTABILITY}

Since the filaments are uniaxially wound and stressed and act elastically to near fallure, their strength and behavior are quite readily predictable. The metal, however, is stressed biaxially and flowing plastically near burst. The constraining effect of the filaments also makes the stress ratio in the metal vary continuous ly after the metal has yielded. The elasticplastic stress-strain behavior of the metal as a function of pressure is, therefore, a difficult problem to solve.

An elastic-plastic stress analysis of overwrapped tanks using the incremental theory of plasticity was presented in ref. 4. Because of the relatively large number of calculations involved, a computer program is desirable to solve the equations. presented there. Since the hoop strains at instability were less than 5 percent and the stress field ratio varied only from about 1.7-to-1 to 1-to-1 for the vessel tests reported herein, it was believed that 
the deformation theory of plasticity could be used to predict instability pressures. Use of the deformation theory would greatly reduce the number of calculations. It was decided, therefore, to perform simple hand calculations using the method of ref. 6 to determine instability pressures. The predictions were then compared with experimental results to determine if the deformation theory produced acceptably correct results.

Some properties of the materials used in the pressure vessel tests are given in table I. The proportions of metal and glass in the vessels, pressures, and resulting pressure vessel efficiencies are presented in table II. Three different burst pressures are given in this table. The first is based simply on the uniaxial ultimate strength of the metal and the original dimensions of the specimen. The instability pressures were calculated using a deformation theory of plasticity, assuming a constant $1-t o-1$ stress field ratio, and using true stress-conventional strain data. The 1-to-1 stress field was assumed because most of the deformation and burst occur when the principal stresses are near this ratio. The third column of pressures in table II is the tabulated experimental data.

Figure 3 is a plot of the burst pressures tabulated in table II. The upper line gives the pressures based simply on the uniaxial ultimate strength of the metal. The dashed line is drawn through the calculated instability pressures. In comparing these two lines, it can be seen that the theoretical instability pressures are about $5 \frac{1}{2}$ percent lower than the pressures based on uniaxial ultimate tensile strength. It should be noted that the theoretical pressures based on uniaxial ultimate strength are higher than experimental burst pressures in all cases; the average being about 10 percent. The calculated instability pressures are unconservative in 12 of the 20 cases, the average disparity for all 20 cases belng less than 4 percent. If the one relatively bad data point (specimen 9) is not considered, the theoretical instability pressures are high, only $2 \frac{l}{2}$ percent

on the average. Considering the scatter in the data, the fact that 11 of these calculations were high and 8 low, and the average discrepancy being only $2 \frac{1}{2}$ percent, the use of deformation theory of plasticity for calculating the instability pressures seems to be substantiated. Note that the vessels indit were cycieà sinuweà resulis that were slightly lower than the uncycled vessels.

\section{COMPRESSIVE BUCKLING}

Another possible mode of failure is compressive buckling due to radial external pressure induced by the constrictive filamentary overwrap. The normal pretension load required in the filaments for winding purposes produces some hoop compressive stress in the metallic portion of the pres- sure vessel. Additional compressive stresses will be induced during the proof pressure cycle, if the elastic limit of the metal is exceeded. Depending on the ratio of burst pressure to proof pressure and the factors of safety specified, the compressive stresses induced during the proofing cycle may be very large or nonexistent. For many propellant tanks designed for relatively low pressures, skin gages are dictated by minimum thicknesses for manufacturing and handling purposes. For those cases, there is little likelihood of saving much, if any, weight by using a filamentary overwrap. Indeed, the overwrapped vessel may be heavier. Greater potential for weight saving exists in high-pressure applications. This is fortunate where buckling considerations are concerned.

Pressure vessels which are to operate at relatively high pressures usually are designed with relatively high safety factors. The proof pressure is thus correspondingly lowered compared with the burst pressure. When the proof pressure is low compared to the burst pressure, the amount of plastic flow taking place is low, and thus, the amount of compressive stress on pressure release will be low. This makes the potential buckling problem less severe.

To determine the seriousness of the buckling problem, tests were run on a rather large number of cylindrical specimens of various materials. Diameters varied from 5 to $12 \mathrm{in}$. and thicknesses from 0.004 to 0.032 in. Correspondingly, diameter-tothickness ratios varied from 175 to 3000 . Materials tested for buckling strengths included aluminum, titanium, nickel, mild steel, and stainless steel. The results of buckling tests on cylinders with constrictive wrap are plotted in fig. 4. It can be seen that a reasonably linear relation exists between diameter-to-thickness ratio and the ratio of critical stress to secant modulus on a $10 \mathrm{~g} \log$ plot of data. This ratio of critical stress to secant modulus corresponds to the total hoop strain at failure.

At the lower diameter-to-thickness ratios $(2 a / h \approx 200)$, some of the specimens buckled inelastically; in addition, some of the higher strength materials failed elastically at strains approaching 1 percent. The corresponding buckling strengths were about 500 times greater than predicted using the classical equation for long, thin tubes subjected to uniform external lateral fluid pressure. At the higher diameter-tothickness ratios (2000 to 3000 ) the data are at least 30 times greater than values obtained from the classical t'luid pressure buckling equation. Since the classical equation gives results which are usually unconservative by a factor of about 2 . buckling stresses due to external filamentary windings are about 60 to 1000 times greater than those due to external lateral fluid pressure for the range of diameter-tothickness ratios investigated herein for long, thin cylindrical tubes.

These data indicate that buckling of the metal liner due to the constrictive wrap may not be a major problem for most overwrapped 
pressure vessels. As mentioned before, the greatest potential for overwrapped tanks is for high-pressure containers. Because of the high pressures and safety factors involved, the diameter-to-thickness ratios will probably be such that adequate margins of safety are maintained against buckling. As can be seen in fig. 4, the critical compressive strains and stresses are near the yield or in the plastic range for diameterto-thickness ratios as high as about 300 or 400 based on the minimum strength curve; that is, critical stress-to-modulus ratios of about $5000 \times 10^{-6}$ to $7500 \times 10^{-6}$ correspond to hoop strains of about $1 / 2$ to $3 / 4$ percent and occur for diameter-to-thickness ratios of about 300 or 400 .

\section{PRESTRESS}

As mentioned previously, the usable elastic strain range of the metal can be extended by prestressing the overwrapped tank. There are basically two ways to induce the prestress: One way is to apply the filaments with a large pretension load; the other way is to permit plastic flow on the proof pressure cycle to build in the prestress. Because of possible tensile instability or other material limitations, it would be desirable to prestress by pretensioning during winding. Unfortunately, materials such as S-HTS glass can be wound at loads only about 25 percent of their ultimate load because of possible damage to the filaments during winding. If a large amount of prestress is required, it therefore has to be obtained by pressurization. Depending on the ratio of proof pressure to burst pressure, however, substantial amounts of prestress may not be required.

If the pressure vessel is to be used for cryogens, a further requirement for prestress exists. The different coefficients of thermal expansion between the filamentary and metaliic materials must be considered. Considering S-HTS glass wound on an aluminum cylinder, the thermal contraction of the aluminum to $-320^{\circ} \mathrm{F}$ is about 3800 $\mu \mathrm{in} . / \mathrm{In}$. and that of the glass about 600 Min./in. The difference in contraction to liquid-nitrogen temperature is therefore about $1 / 3$ percent strain. Special winding techniques are required to obtain prestrains significantly greater in magnitude because of fraying and damage to rovings during winding. Thus, if the vessel is wound at room temperature with near-maximum prestrain, most of the prestress will be lost at cryogenic temperatures. In practice, some prestress will probably be obtained through both of the methods discussed.

\section{PRESSURE VESSEL TESTS}

\section{Scale Model Vessels}

To verify the potential gains in pressure vessel efficiency theorized to be possible in the section STRESS ANALYSIS, a number of small-scale overwrapped cylindrical pressure vessels were tested to burst. The metal cylinders were made by machining 5.6-in.diameter cylinders from extruded 2014-T6 aluminum tubing. The cylinders were then wrapped with S-HTS glass impregnated with epoxy resion to form a layer of fiberglassreinforced plastic (FRP). Removable ends for closures were then attached to the overwrapped cylinders. The uniaxial material properties of the aluminum and fiberglass composite are presented in table I for room and cryogenic temperatures.

Most of the vessels were wrapped with an amount of FRP just sufficient, based on uniaxial tensile properties, to carry onehalf of the hoop load due to pressure at the burst condition. This amount of FRP is referred to herein as optimum. Some of the cylinders were wrapped with only 85 or 90 percent of the optimum amount of FRP to determine the influence of the amount of overwrap on the burst pressure and the pressure vessel efficiency. Some vessels were pressurized monotonically to burst, while others were pressure cycled and then pressurized to burst. The effects of varying these parameters on pressure vessel performance will be discussed in subsequent paragraphs.

The theoretical thickness of the optimum amount of composite was usually about onethird of the metal thickness for the material properties associated with these test vessels. Examination of table II reveals that the nominal measured thickness was substantially greater than this. The reasons for the discrepancy are primarily the measurement inaccuracies associated with such thin layers of composite along with the resulting greater effect of surface roughness on the measured thickness. For manufacturing purposes, the amount of glass was determined simply by giving the number of ends per inch necessary to carry half of the hoop load." In computing the experimental pressure vessel efficiencies, the weight of the glass was determined by measurement rather than theoretical use of thickness and density.

\section{Test Results}

The results of the pressure vessel tests are shown in fig. 5, where pressure vessel efficiency $\mathrm{pV} / \mathrm{W}$ is plotted against test temperature. The lower band represents the results of burst tests of unwrapped 2014-T6 aluminum cylinders. The upper band encompasses all but one of the half-cycle burst tests of S-HTS glass overwrapped 2014-T6 aluminum vesscls. The one particularly low results at liquid nitrogen temperature was still about 15 percent more efficient than the unwrapped tanks. Note that all other efficiencies are from 30 to 50 percent better than the test results of unwrapped cylinders.

All three vessels tested at liquid hydrogen temperature had what was defined as an optimum amount of glass. The results showed little scatter and were about 50 percent higher than those for smooth 2014-T6 tanks. 
At room temperature, vessels with the optimum amount of glass and with 85 percent of the optimum amount were tested to burst. The results for both groups of tanks are about the same, with the 85 percent cylinders having perhaps a slightly higher efficiency.

At liquid-nitrogen temperatures, tanks with the optimum amount of glass and with 90 percent of that amount were tested. Some of them were tested simply half-cycle to burst; others were pressure cycled 25 to 50 times at 70 percent of the burst pressure with one to three warmups interspersed during the cyclic testing. As can be seen in fig. 5, the efficiencies for the cycled vessels are slightly lower than for those pressurized directly to burst. It appears, therefore, that there has been a slight reduction in performance due to the cyclic history. One reason why the reduction in performance has been so small is that the number of cycles imposed was relatively small. Another reason is that the glass is wrapped and stressed essentially unlaxially. Thus, the strength of the glass, which usually decreases with cyclic life in biaxially wound tanks, is not noticeably reduced when wound only circumferentially on metallic cylinders and cycled in liquid nitrogen. The windings do overlap each other but at an extremely small angle and a considerably reduced number of times.

Note that there is excellent agreement between theoretical and experimental pressure vessel efficiencies for the homogeneous 2014-T6 aluminum tanks at all three test temperatures: The pressure vessel efficiencies for the overwrapped tanks calculated using equation (11) are unconservative by about 10 percent when compared with the best experimental results. This is because uniaxial ultimate strengths developed at relatively high strains were substituted into the equation. In practice, the instability strength developed in the metal was about 10 percent less than uniaxial ultimate strength. Using critical stresses developed theoretically in the tensile instability analysis of the overwrapped vessels, the overwrapped cylinders were about 50 percent more efficient than the unwrapped 2014-T6 tanks. This figure is in very good agreement with the best experimental data obtained at the three test temperatures.

Perhaps if a greater statistical sampling of tests were run with various amounts of overwrap and with various cyclic histories, the effects of varying these parameters would be more pronounced. However, the results of 20 pitessuife vessel tests repoited here certainly indicate that there is a potential for a significant weight reduction by using overwrapped tanks in high-pressure applications. In addition, the overwrapped cylinders are relatively simple and inexpensive to fabricate.

\section{Fracture}

The vessels with an optimum amount of glass were designed to have the metal and filaments reach their ultimate strengths simultaneously. Since the metal is designed to be in a 1-to-l stress field at burst pressure, the failure orientation in the metal is not readily predictable. In cylinders wound with the optimum amount of glass, fracture usually originated in the metal. Where less than the optimum amount of glass was used, the fractures seemed to originate in the aluminum about as often as in the glass. The metal failures were either longitudinal or circumferential or, in many cases, both.

Figure $6(\mathrm{a})$ shows a cylinder with an optimum amount of glass which was tested at room temperature. Two of the four cylinders so tested failed due to hoop stress in the metal without the glass subsequently breaking. Presumably the glass load would be about twice what it was designed to take when the metal carrying half of the hoop load fractured. Actually, it appeared that the resin had crazed during straining and allowed the pressure to escape after the aluminum failed, permitting the glass to remain intact.

Fig. $6(\mathrm{~b})$ is a view of a vessel with an optimum amount of glass pressurized when filled with liquid nitrogen. In this case the metal failed because of longitudinal stress. As can be seen, the fracture has a sawtooth pattern. In several cases, the failure was smooth circumferentially almost as if cut by a knife. The removable ends and strain gage wires shown here are typical for the tests.

A vessel with 90 percent of the optimum amount of glass, which was also tested in liquid nitrogen, is shown in $\mathrm{fig} .6(\mathrm{c})$. This failure is typical of several of the tests. The glass appears to have ruptured first, allowing the aluminum to bulge because of plastic flow and then, subsequently, fracture.

The failure shown in fig. $6(d)$ is typical of all three vessels tested in liquid hydrogen. A fluid volume reducer (ref. 7) was. inserted in these vessels during test and permitted an annulus of only $1 / 4$ in. of $1 i$ quid hydrogen to be in contact with the test specimen. In addition, internal chambers were used to trap the gaseous helium used to pressurize the cylinder and assure a hydraulic failure. In spite of these precautions, the failures were catastrophic, as can be seen.

\section{SAFETY FACTORS}

Safety factors for the glass stresses and hoop and longitudinal stresses in the metal at $-320^{\circ} \mathrm{F}$ were calculated. These factors are shuwi lin fig. 7 as a iniction of the pressure safety factor (ratio of the failure to operating pressure) for various proof to operating pressure ratios. These safety factors were determined by first constructing a curve of metal stress versus proof pressure, using strain gage data obtained from a tank burst test. If experimental data were not available, a curve could be assumed between the stress at yield pressure and the stress at burst pressure, as calculated by the deformation method of ref. 6 for a 1 -to-1 stress field ratio. 
From the stress-pressure curves, the instantaneous strains can be calculated for any proof pressure by using the general equations of ref. 6. Assuming the principle of superposition for elastic unloading, the stresses at any operating pressure can be calculated for any given proof pressure. Both the glass (figs. $7(a)$ and.(b)) and the metal longitudinal stress safety factors (fig. $7(\mathrm{c})$ ) decrease with decreasing pressure safety factor for a given ratio of proof to operating pressure, as would be expected. The safety factors on longitudinal stress in the metal vary with proof pressure because of dimensional changes taking place due to plastic flow at proof pressure. The dashed lines in $\mathrm{fig} .7$ represent envelopes or boundaries beyond which the curves cannot go because they would call for proof pressures greater than the burst pressures.

In fig. 7(b), the glass curves of fig. $7(a)$ are expanded in the region of low safety factors, which is of primary interest. A limit curve is also plotted, showing where the glass or metal safety factors are critical. To determine the actual stress safety factor in the metal, both the hoop and longitudinal stresses must be considered. Another limit curve is plotted in fig. $7(d)$ showing where the longitudinal or hoop spresses are maximum in the metal.

The metal-hoop stress-safety-factor curves of fig. 7(d) exhibit some trends that are not immediately obvious. One of these effects is that for a constant pressure safety factor, the stress safety factor increases with increasing proof pressure. The reason for this is that the higher the proof stress, the greater the residual compressive stress in the metal on unloading and the smaller the metal hoop stress when the tank reaches a given operating pressure on reloading.

Another trend in fig. $7(d)$ which may at first seem surprising is that with a constant proof-to-operating-pressure ratio, the hoop stress safety factor actually decreases under some conditions as the pressure safety factor is increased. This effect occurs when the proof pressure is near failure or on the flat part of the metal stress-strain curve. The reason for this is basically the same as that given above except that instead of a constant pressure safety factor, there is a constant ratio of proof to operating pressure.

Fig. 7 indicates that it may be feasible to operate at low stress safety factors. As an example, assume that the operating pressure is to be $1000 \mathrm{lb} / \mathrm{in} .2$, the proof pressure iivo ióin.2, ana tine railure pressure is to be $1600 \mathrm{Ib} / \mathrm{in.2}$. For $\mathrm{p}_{\mathrm{b}} / \mathrm{p}_{\mathrm{o}}=1.6$ and $\mathrm{p}_{\mathrm{p}} / \mathrm{p}_{\mathrm{o}}=1.1$ in $\mathrm{f} 1 \mathrm{~g} .7$, the stress safety factors are 3.5 in the glass and 1.16 on the hoop press in the metal. Even though there is only a 16-percent margin of safety on stress at the operating condition, there is a

60-percent margin of safety on pressure.

It is also desirable to check the safety factors at the proof pressure, since the tank could fail on the first proof cycle. This can be done directly from fig. 7 for the preceding example by assuming that the proof pressure is also the operating pressure. Thus, for $p_{b} / p_{p}=1600 / 1100=1.45$ and $p_{p} / p_{o}=1.0$, the stress safety factors are 3.3 in the glass and 1.03 in the metal. Even though the margin of safety on stress is only 3 percent, on the basis of pressure it is 45 percent. The margin of safety based on stress is thus misleading.

\section{PRESSURE VESSEL EFFICIENCY AS A}

\section{FUNCTION OF LENGTH}

The pressure vessel efficiencies $\mathrm{pV} / \mathrm{W}$ discussed to now have been for very long cylinders, where the effect of the ends could be neglected. Since the pressure vessel is wound only on the cylindrical portion with circumferential windings, unwrapped ends with the highest pressure vessel efficiency would be hemispherical in shape. Since the wrapped cylinder has a higher efficiency than the hemispherical domes, the effect of accounting for length and ends is a reduction in the pressure vesisel efficiencies below those previously presented. The results of calculations for pressure vessel efficiency at liquidnitrogen temperature of 2014-T6 aluminum cylinders overwrapped with S-HTS glass and having hemispherical domes are presented in fig. 8. The reduced efficiency of short vessels is clearly shown. The thlckness of glass composite was based on the stress at instability in the metal, not on metal uniaxial ultimate strength. The thickness of the domes in both cases was adjusted to give the same burst pressure as the cylinder. The maximum efficiency ratio of about 1.5 for long cylinders agrees well with the best experimental results based on the efficiencies shown in fig. 4.

\section{CONCLUSIONS}

The following conclusions were deduced from the theoretical and experimental study of filament-overwrapped metallic cylindrical pressure vessels described in this. paper:

1. Filament-overwrapped metallic cylindrical pressure vessels can be more efficlent than spherical pressure vessels made of the same metallic material.

2. 2014-T6 aluminum cylinders wrapped with S-HTS glass were proved by experiment to be as much as 50 percent more efficient than homogeneous 2014-T6 aluminum cylindrical pressure vessels.

3. The deformation theory of plasticity can be used to determine instability pressures for overwrapped cylindrical pressure vessels within a reasonably"small error.

4. The buckling strengths of metal cylinders subjected to constrictive filamentary compressive stresses are many times higher than when they are subjected to external fluid pressure. The ratios of the buckling strengths for constrictive wrap compared to external fluid pressure are about 1000 and 60 for diameter-to-thickness ratios of 
about 200 and 2000 , respectively.

5. Safety factors based on pressure may be considerably higher than those based on stress for overwrapped pressure vessels. Consequently, margins of safety based on stress may be misleading.

\section{REFERENCES}

1. Farre11, J. W. and Howle, C. E., "Segmented Sphere Pressure Containers. ARS Paper 2428-62 (April 1962).

2. Bert, C. W., "Large Weight Reductions Possible in Pressure Vessels," Space/ Aeronautics, 38, pt. 1, 77-83 (October 1962).

3. Odell, C. N. and Albert, W. E., "The Filament-Reinforced Motor Case," Aerospace Eng., 21, 52 (April 1962).

4. Wolff, F. and Harvey, A., "Prestressed Fiber-Metal Cylindrical Pressure Vessels," ASME Paper 63-AHGT-70 (March 1963).

5. Gerard, G., "Aerospace Pressure Vessel Design Synthesis," NASA CR-287 (1965).

6. Kaufman, A. and Spera, D. A., "Invest1gation of the Elastic-Plastic Stress State Around a Reinforced Opening in a Spherical Shell," NASA TN D-2672 (1965).

7. Calvert, H. F. and Kemp, R. H. "Determination of Pressure Vessel Strengths at $-423^{\circ} \mathrm{F}$ as Influenced by Notches of Various Radi1." SAE Preprint 520B (Apr11 1962).

8. Langhaar, H., Boresi, A., Marcus, L. and Love, G., "Buckling of a Long Fiber-Wound Cylindrical Shell Due to Stresses Caused by Windings," J. Appl. Mech., 32, 81-86 (March 1965). 
TABLE I. - MATERIAL PROPERTIES

\begin{tabular}{|c|c|c|c|c|c|c|}
\hline Material & $\begin{array}{l}\text { Density, } \\
\text { lb/in. } 3\end{array}$ & $\begin{array}{l}\text { Temper- } \\
\text { ature, } \\
\mathrm{O}_{\mathrm{F}}\end{array}$ & $\begin{array}{c}\text { Yield } \\
\text { strength, } \\
\text { lb/In.2 }\end{array}$ & $\begin{array}{c}\text { True } \\
\text { ultimate } \\
\text { tensile } \\
\text { strength, } \\
\text { lb/in.? }\end{array}$ & $\begin{array}{c}\text { Elonga- } \\
\text { tion } \\
\text { (2 in. } \\
\text { gage } \\
\text { length) } \\
\text { in./in. }\end{array}$ & $\begin{array}{l}\text { Modulus of } \\
\text { elasticity, } \\
\text { Ib/in.? }\end{array}$ \\
\hline $\begin{array}{l}\text { 2014-T6 } \\
\text { Aluminum }\end{array}$ & 0.101 & $\begin{array}{c}70 \\
-320 \\
-423 \\
\end{array}$ & $\begin{array}{l}70,000 \\
82,000 \\
91,000\end{array}$ & $\begin{array}{r}76,000 \\
94,000 \\
108,000 \\
\end{array}$ & $\begin{array}{c}0.093 \\
.100 \\
.100^{*}\end{array}$ & $\begin{array}{l}10.9 \times 10^{6} \\
12.1 \\
12.0\end{array}$ \\
\hline $\begin{array}{l}\text { S-HTS } \\
\text { Glass } \\
\text { composite }\end{array}$ & 0.073 & $\begin{array}{l}70 \\
-320 \\
-423\end{array}$ & 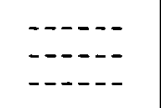 & $\begin{array}{l}281,000 \\
331,000 \\
298,000\end{array}$ & $\begin{array}{r}0.045 \\
.053 \\
.051\end{array}$ & $\begin{array}{l}8.2 \times 10^{6} \\
8.8 \\
9.6\end{array}$ \\
\hline
\end{tabular}

* Assumed.

TABLE II. - GEOMETRY, BURST PRESSURES, AND EFFICIENCIES FOR 5.6-IN.-DIAMETER S-HTS GLASS-OVERWRAPPED 2014-T6 ALUMINUM VESSELS

\begin{tabular}{|c|c|c|c|c|c|c|c|c|c|}
\hline \multirow{3}{*}{$\begin{array}{c}\text { Speci- } \\
\text { men }\end{array}$} & \multirow{3}{*}{$\begin{array}{c}\text { Temper- } \\
\text { ature } \\
\text { OF }\end{array}$} & \multirow{3}{*}{$\begin{array}{l}\text { Metal } \\
\text { thick- } \\
\text { ness, } \\
\text { In. }\end{array}$} & \multirow{3}{*}{$\begin{array}{c}\text { Glass } \\
\text { composite } \\
\text { thickness } \\
\text { (approx) } \\
\text { in. }\end{array}$} & \multirow{3}{*}{$\begin{array}{c}\text { Glass, } \\
\text { ends } \\
\text { per } \\
\text { inch }\end{array}$} & \multirow{3}{*}{$\begin{array}{l}\text { Glass, } \\
\text { percent } \\
\text { of opti- } \\
\text { mum }\end{array}$} & \multicolumn{3}{|c|}{ Brust pressure, $1 \mathrm{~b} / \mathrm{in} .^{2}$} & \multirow{3}{*}{$\begin{array}{c}\text { Efficiency } \\
\left(\mathrm{p}_{\mathrm{b}} \mathrm{V} / \mathrm{W}\right) \exp , \\
\text { in. }\end{array}$} \\
\hline & & & & & & \multicolumn{2}{|c|}{ Theoretical } & \multirow{2}{*}{$\begin{array}{l}\text { Experi- } \\
\text { mental }\end{array}$} & \\
\hline & & & & & & $2 \sigma_{u} h / a$ & Instability & & \\
\hline $\begin{array}{r}1 \\
2 \\
3 \\
4 \\
5 \\
6 \\
7 \\
8 \\
9 \\
10 \\
11 \\
12 \\
13 \\
14 \\
15 \\
16 \\
17 \\
18 \\
19 \\
20\end{array}$ & $\begin{array}{l}-423 \\
-423 \\
-423\end{array}$ & $\begin{array}{r}0.0319 \\
.0319 \\
.0314 \\
.0315 \\
.0312 \\
.0316 \\
.0315 \\
.0321 \\
.0315 \\
.0222 \\
.0317 \\
.0321 \\
.0219 \\
.0380 \\
.0313 \\
.0380 \\
.0380 \\
.0320 \\
.0323 \\
.0315\end{array}$ & $\begin{array}{l}0.015 \\
. \\
.012 \\
.012 \\
.012 \\
.017 \\
.016 \\
.012 \\
.015 \\
.015 \\
.013 \\
.017 \\
.012 \\
.016 \\
.018 \\
.015 \\
.015 \\
.014\end{array}$ & $\begin{array}{l}1 \\
300 \\
300 \\
300 \\
350 \\
350 \\
240 \\
350 \\
350 \\
240 \\
378 \\
315 \\
378 \\
378 \\
400 \\
400 \\
400\end{array}$ & $\begin{array}{r}100 \\
\downarrow \\
85 \\
85 \\
85 \\
100 \\
1\end{array}$ & $\begin{array}{l}1740 \\
1740 \\
1713 \\
1719 \\
1702 \\
1724 \\
1719 \\
2155 \\
2115 \\
1488 \\
2129 \\
2155 \\
1468 \\
2555 \\
2102 \\
2555 \\
2555 \\
2481 \\
2504 \\
2442\end{array}$ & $\begin{array}{l}1645 \\
1645 \\
1618 \\
1624 \\
1608 \\
1629 \\
1624 \\
2037 \\
1999 \\
1406 \\
2012 \\
2037 \\
1387 \\
2414 \\
1986 \\
2414 \\
2414 \\
2348 \\
2370 \\
2311\end{array}$ & $\begin{array}{l}1675 \\
1518 \\
1635 \\
1490 \\
1650 \\
1544 \\
1450 \\
2028 \\
1550 \\
1380 \\
2060 \\
1853^{*} \\
1318^{*} \\
2363 \\
2043 \\
2365^{*} \\
2233^{*} \\
2345 \\
2340 \\
2358\end{array}$ & $\begin{array}{l}564,000 \\
510,000 \\
573,000 \\
521,000 \\
593,000 \\
551,000 \\
519,000 \\
693,000 \\
539,000 \\
683,000 \\
706,000 \\
633,000 \\
660,000 \\
698,000 \\
729,000 \\
703,000 \\
660,000 \\
786,000 \\
781,000 \\
802,000\end{array}$ \\
\hline
\end{tabular}

* Cycled. 
co

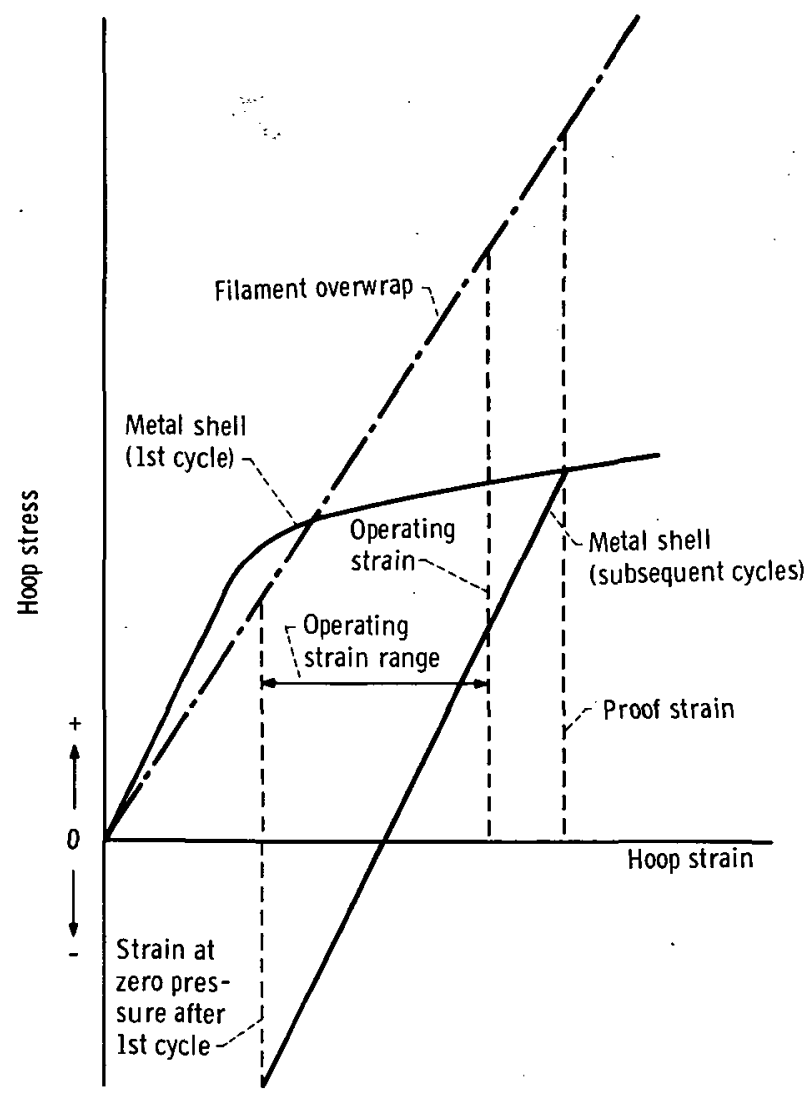

Figure 1. - Stress-strairi curves for filament-overwrapped metallic pressure vessel. 


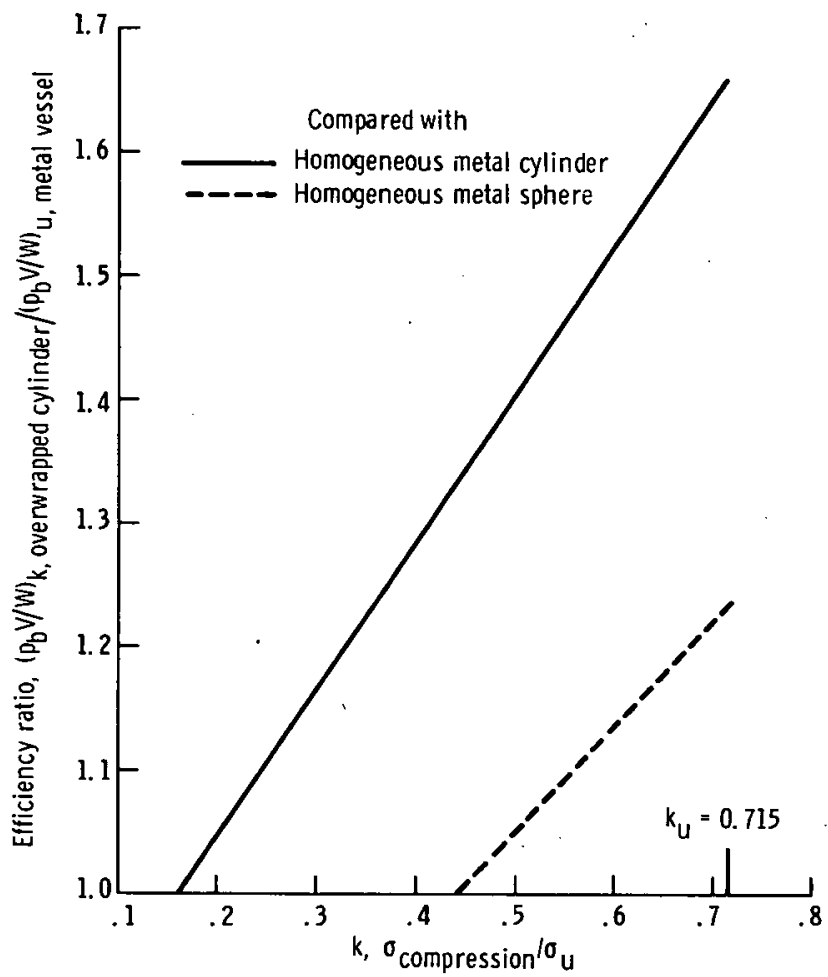

Figure 2. - Efficiency ratio as function of allowable compressive stress ratio for 2014-T6 aluminum pressure vessels overwrapped with S-HTS glass and proofed to near burst at $-320^{\circ} \mathrm{F}$. 


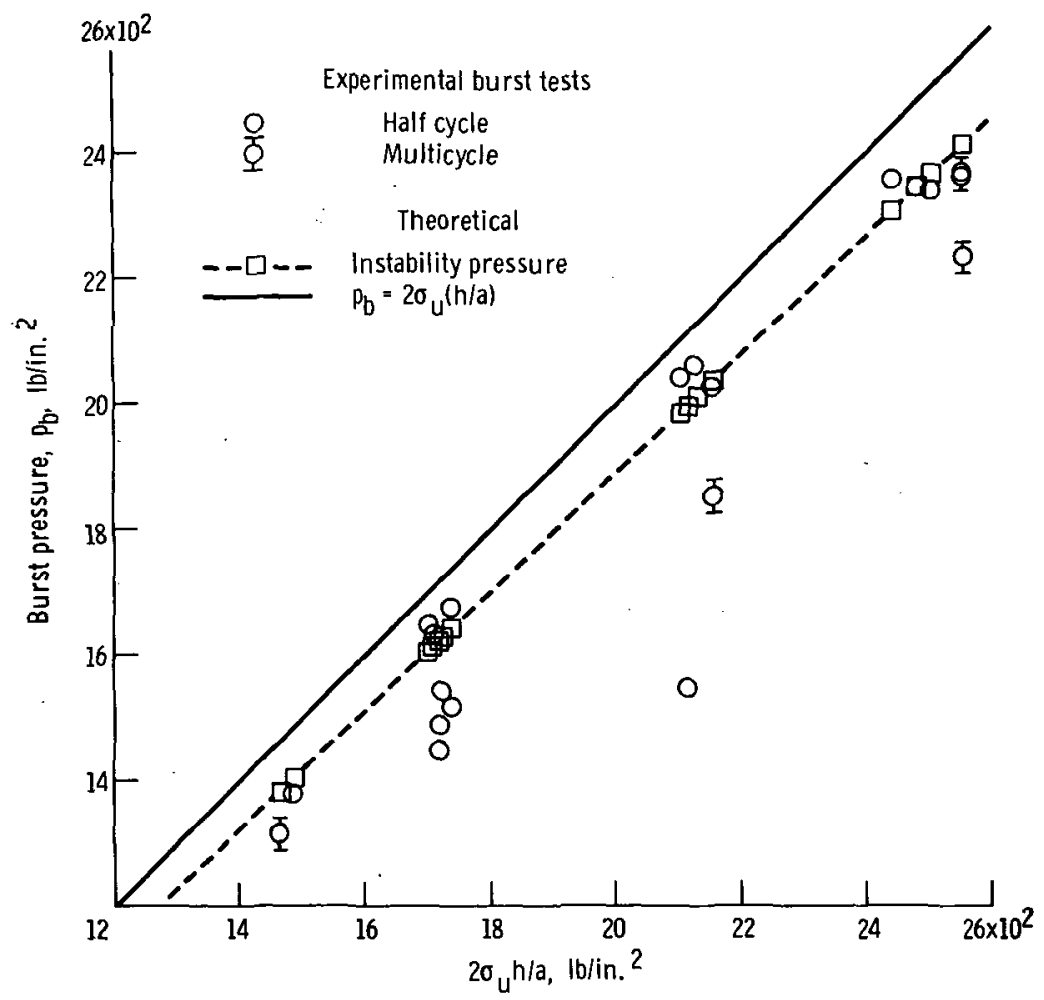

Figure 3. - Experimental and theoretical failure pressures as function of metal ultimate tensile strength and geometry for 2014-T6 aluminum pressure vessels overw rapped with S-HTS glass. 
0
1
$n$
0
1
1

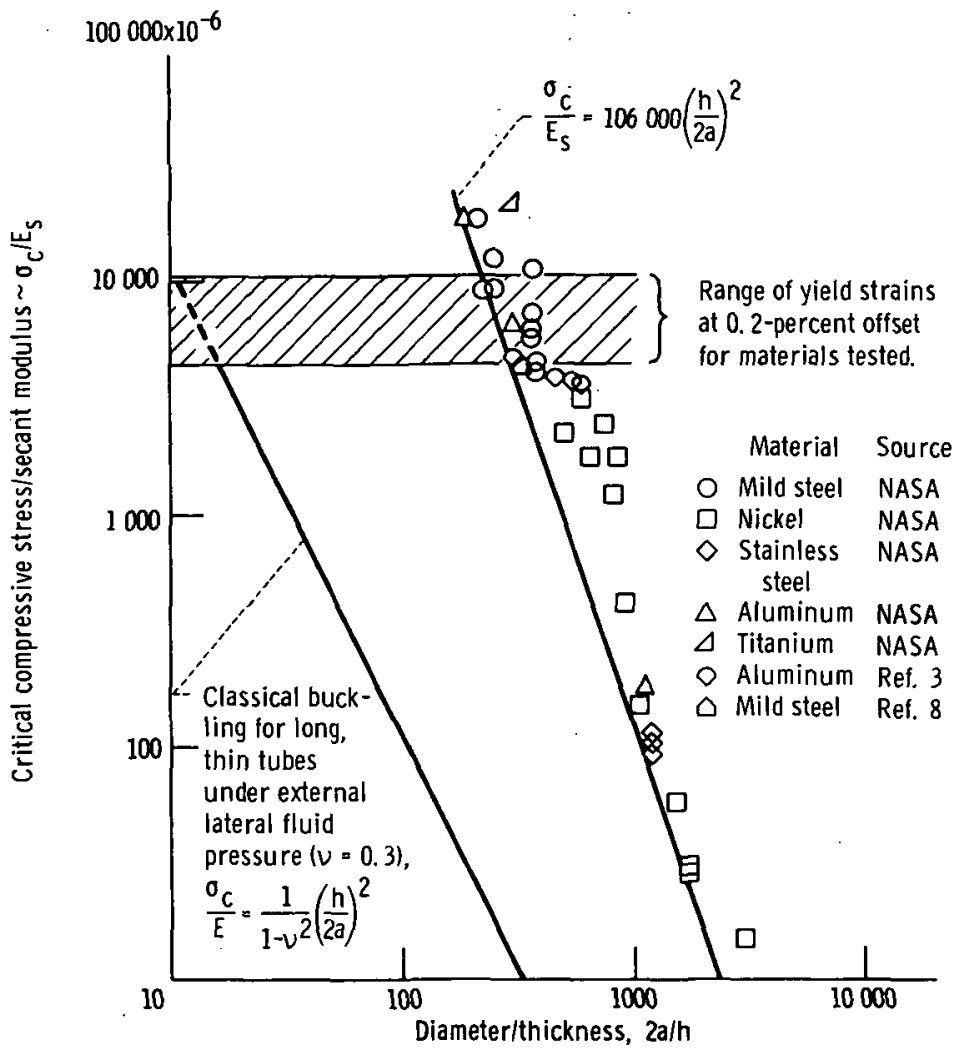

Figure 4. - Constrictive wrap buckling strengths for cylindrical tubes. 


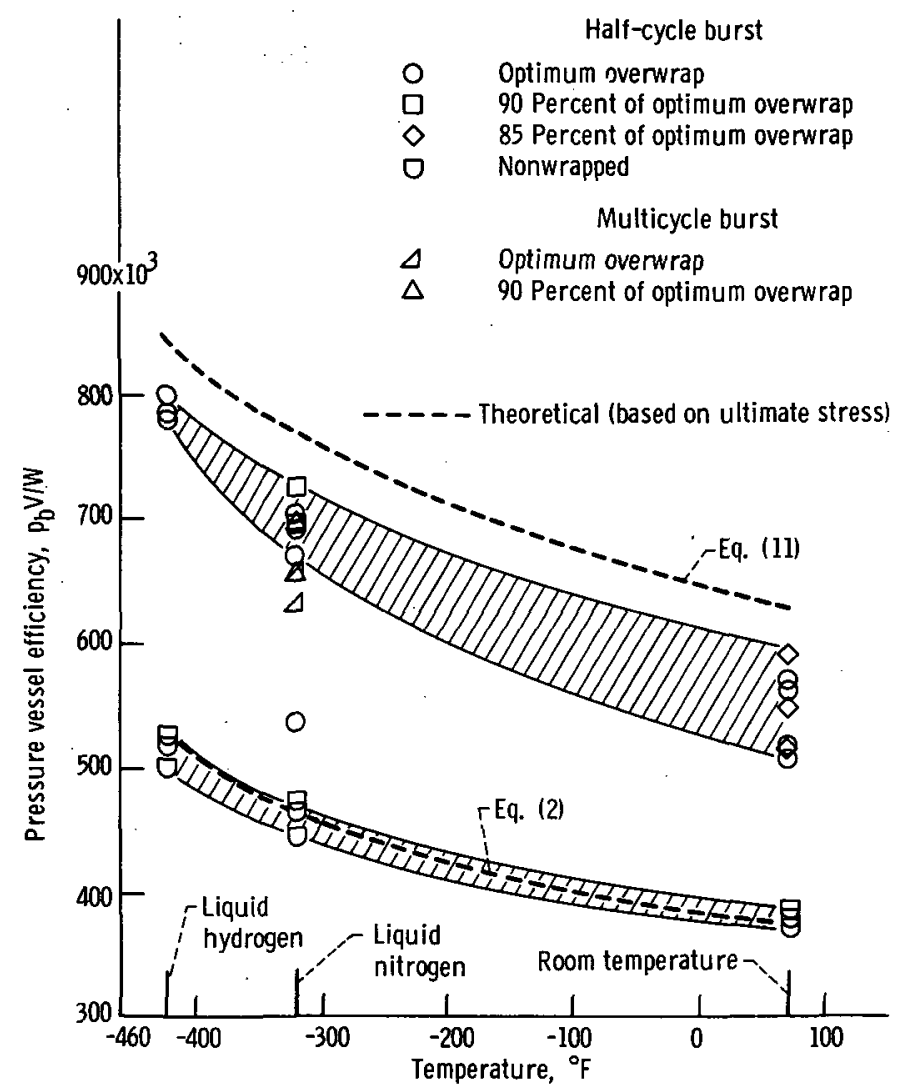

Figure 5. - Pressure vessel efficiencies at burst for S-HTS glassoverwrapped and nonwrapped 2014-T6 aluminum pressure vessels. 


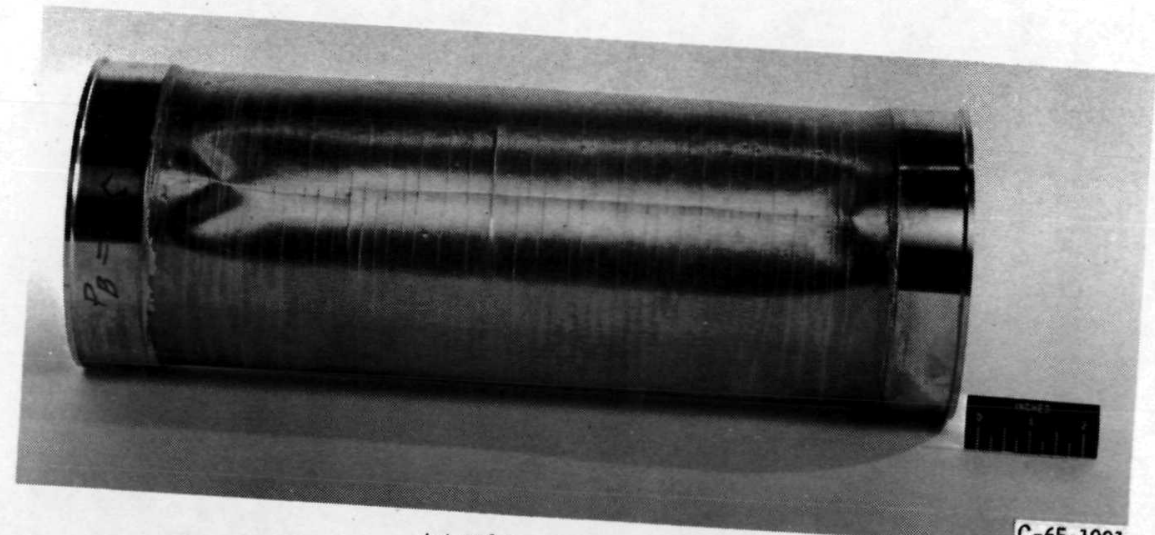

(a) $70^{\circ} \mathrm{F}$, optimum overwrap.

C-65-1091

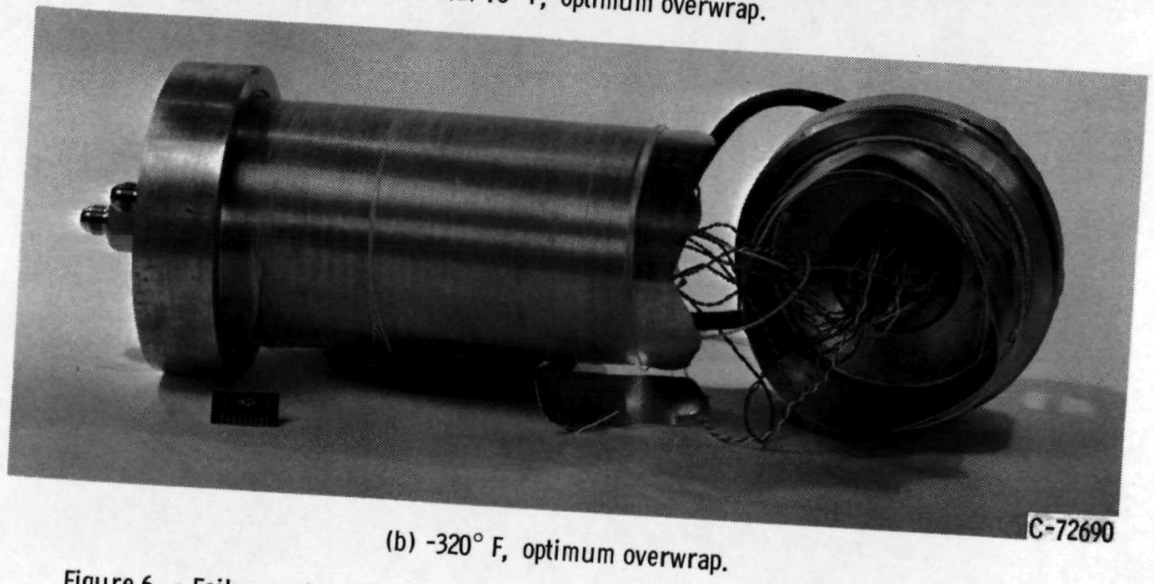

Figure 6. - Failures of 2014-T6 aluminum pressure vessels overwrapped with S-HTS glass. 
ce

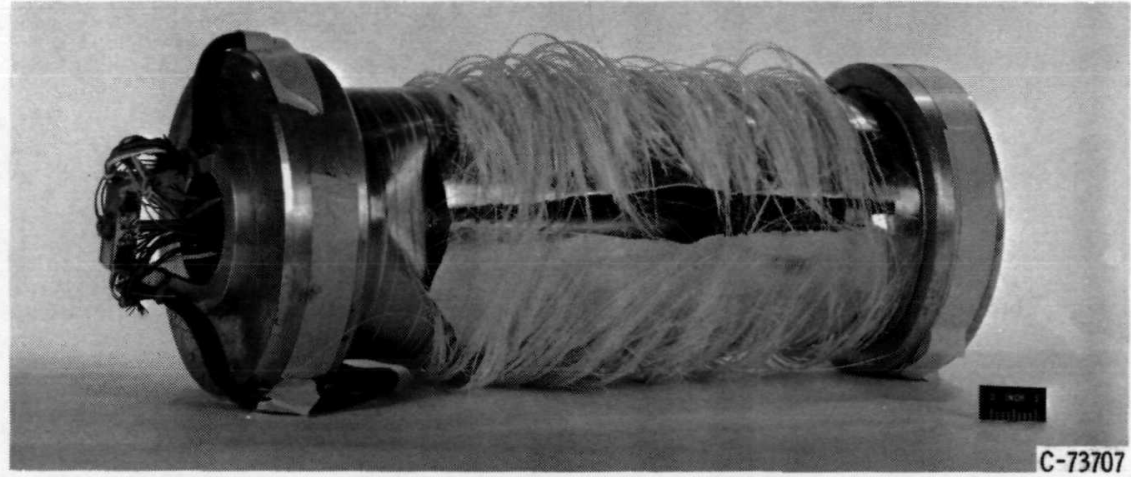

(c) $-320^{\circ} \mathrm{F}, 90$ percent of optimum overwrap.

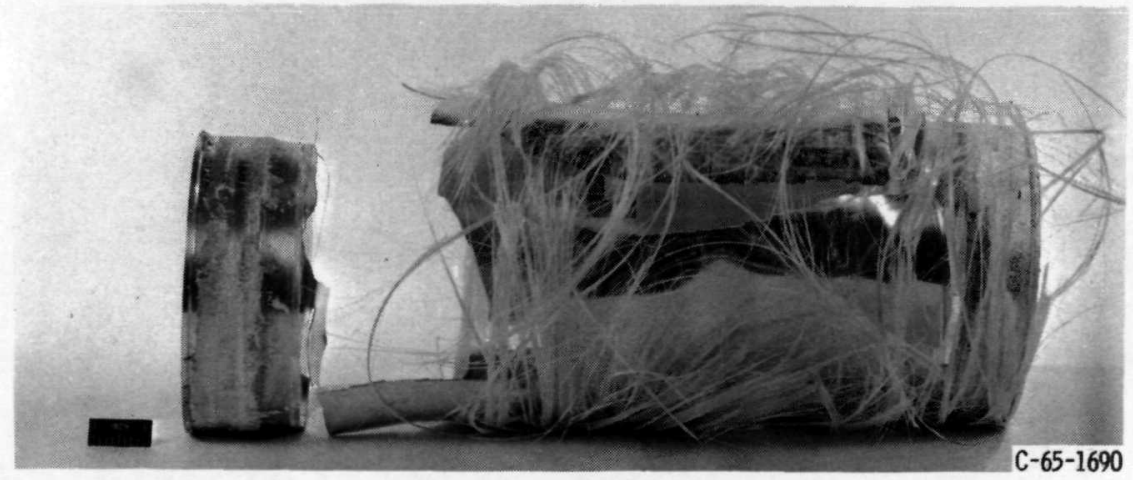

(d) $-423^{\circ} \mathrm{F}$, optimum overwrap.

Figure 6. - Concluded. 
0
1
$n$
1
1
cy

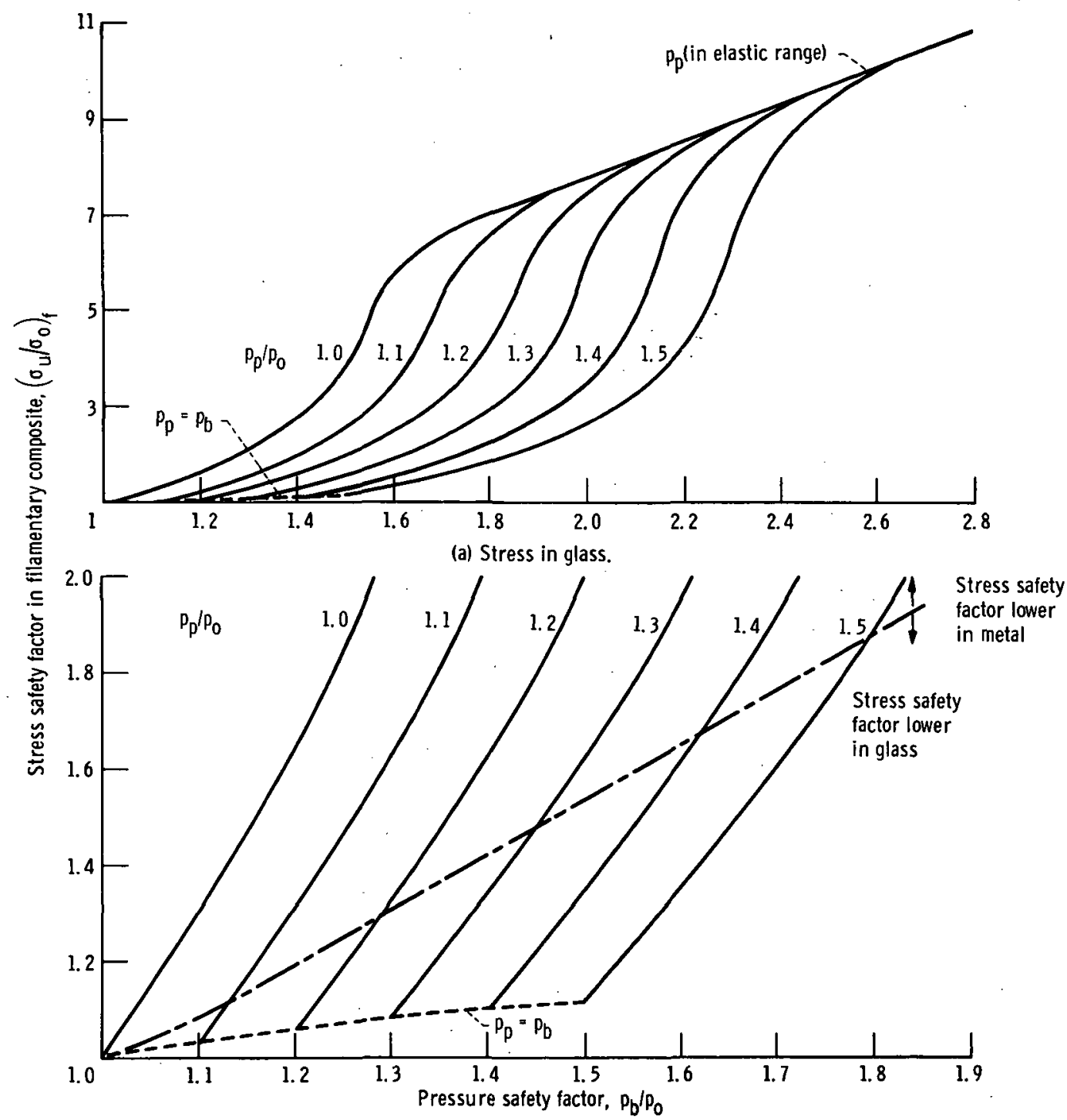

(b) Stress in glass (expanded).

Figure 7. - Stress safety factor as function of pressure safety factor for 2014-T6 aluminum pressure vessels overwrapped with S-HTS glass and tested at $-320^{\circ} \mathrm{F}$. 
ç
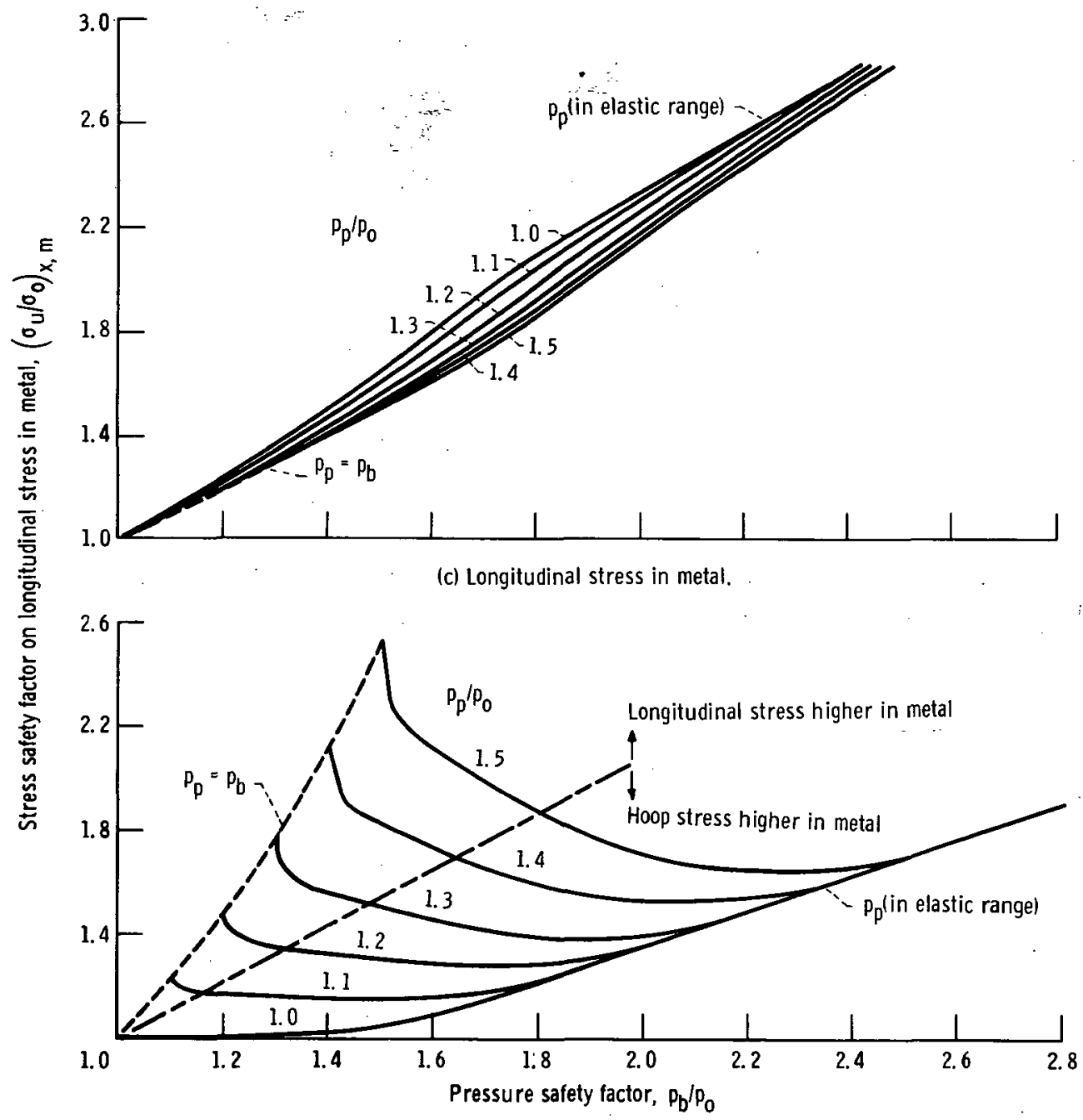

(d) Hoop stress in metal.

Figure 7. - Concluded. 


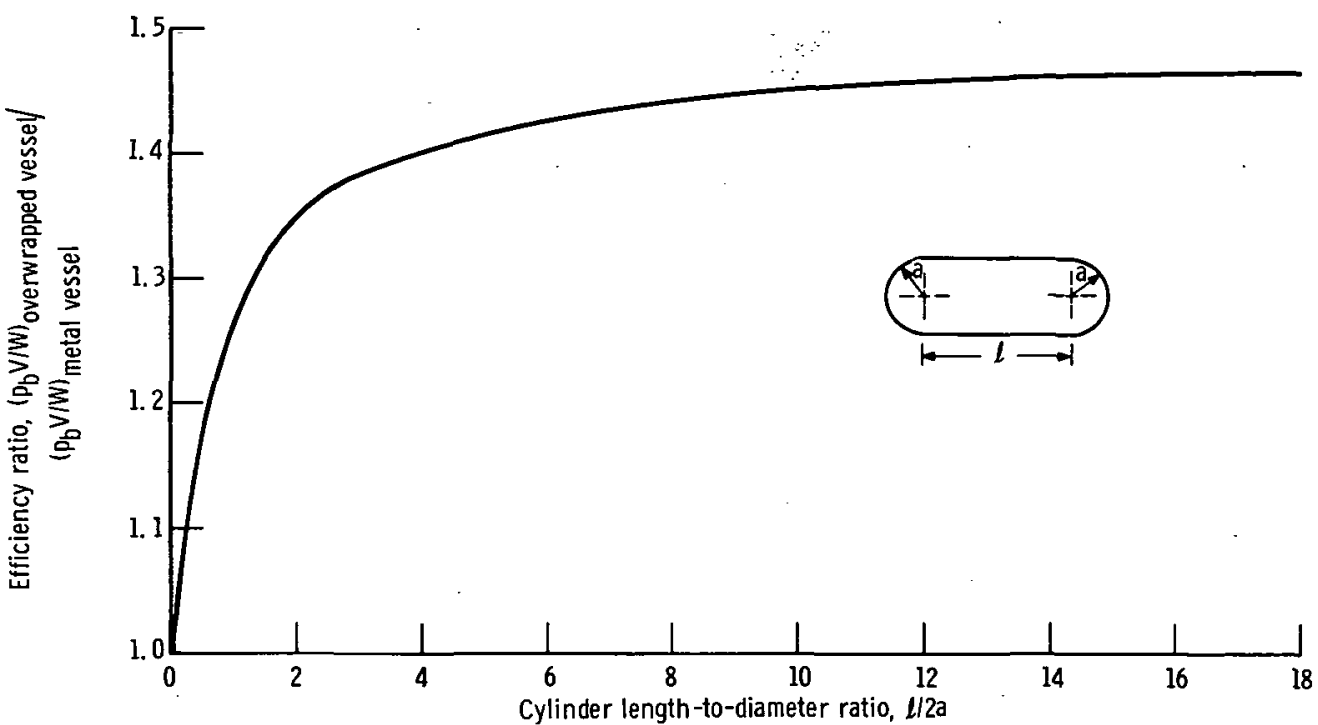

Figure 8. - Efficiency ratio as function of cylinder length to diameter for 2014-T6 aluminum pressure vessels overwrapped with $\mathrm{S}$-HTS glass and tested at $-320^{\circ} \mathrm{F}$. 